\title{
A framework for excellence
}

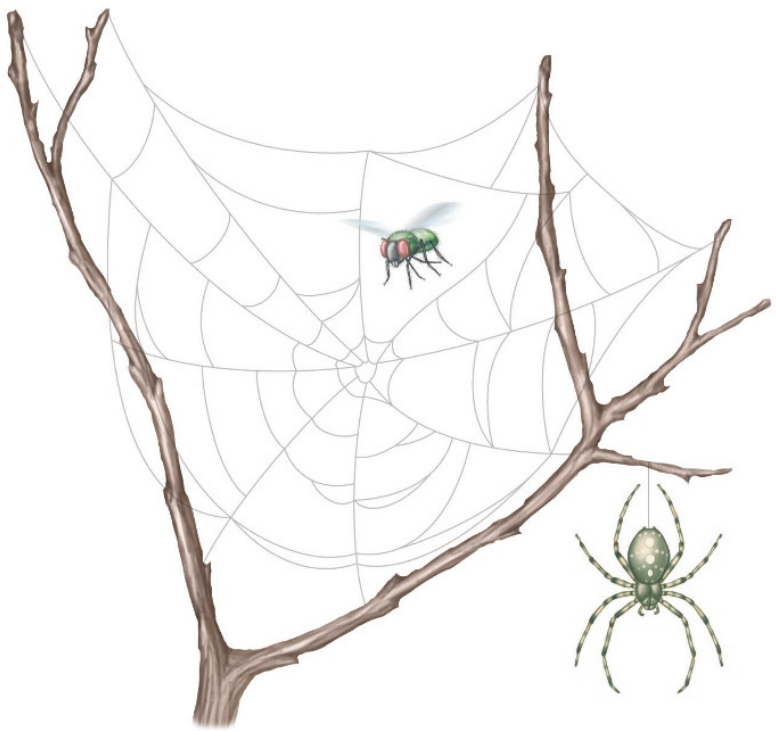

Few scientists are rich enough to ignore new sources of funding, even if they come with strings attached. But your attitude to the European Union's Sixth Framework Programme (FP6) for dispensing European research funds over the next five years may depend on whether you like working in large, all-inclusive collaborations. And 'large' is the operative word - the new 'Networks of Excellence' sought by the EU are intended to incorporate hundreds of researchers. As a naturally multidisciplinary field, materials science could be one of the success stories of this drive for greater pan-European research integration, particularly in those subject areas that rely on significant input from multiple disciplines, such as biomaterials, photonics and electronic materials.

FP6 has a budget of $€ 17.5$ billion, an increase of $€ 2$.6 billion over its predecessor (FP5). Although this is greatly overshadowed by the $€ 120$ billion budget gap between R\&D in the USA and Europe, the allocation of specific funds to key fields such as multifunctional materials, nanotechnology and sustainable development is welcome, as is the rationale behind the requirements for obtaining funding. Individual collaborations, as in previous Framework Programmes, must demonstrate significant cross-border activity between member or associated states, with, crucially, a commitment to developing long-term collaborations. This, Brussels hopes, will effect the idea of the 'European Research Area', a bold proposal that aims to re-engineer the structure of research in Europe and to break down the parochial attitudes that currently

WILL THE STRUCTURESBRUSSELS ISTRYINGTOWEAVEFORTHE EUROPEAN RESEARCHAREAHANG TOGETHER EFFECTIVELY ORWILL THEY OVER-REACHTHEMSELVES AND SPIN OUT OF CONTROL?

ILLUSTRATIONBY DEBBIEMAIZELS cause fragmentation of research effort and prevent greater cooperation between scientists in member states. If successful, the EU and its member states could take advantage of a more coherent infrastructure by increasing R\&D funding to compete on better terms with the USA and Japan.

As Günter Reiter and colleagues highlight in their commentary on page 67 of this issue, integration is just as crucial to the success of FP6 as the actual scientific advances that are expected to result. They point out the many benefits that may result from a well-run Network of Excellence. These include the ability to set far more challenging practical and intellectual goals than can be considered by a smaller research group alone, and the opportunity to create bridges between researchers in very different disciplines, which would otherwise be difficult to build. Another key concept is the development of 'critical mass' - that is, bringing together enough researchers and resources in a given Network to enable rapid and significant progress.

But how does one judge the 'critical mass' required for a productive collaboration in a particular field of materials science? With Brussels seeking proposals for Networks of Excellence that involve up to 1,000 researchers, many materials scientists in Europe are worried about the potentially unwieldy nature of the collaborations, not to mention the possible dilution of the 'excellence' they will supposedly represent. Collaboration between key research groups is always welcome, but if a successful funding application depends upon the inclusion of groups with lesser track records to 'make up the numbers' and to ensure sufficient Europe-wide representation, this may deter the 'best' groups from participating.

The bureaucracy involved in managing such enormous collaborations is also a cause for concern. Whereas smaller collaborations between, say, five or six teams can be managed internally, directing a team of several hundred researchers towards strategic goals will require numerous administrators, thus taking money away from actual research. A final worry comes from the way that the proposals are to be selected and refereed. Brussels is calling for experts to apply to become involved in the assessment stage, but some researchers are concerned that this will mean Network proposals being refereed by people who aren't leaders in their fields or who aren't in a suitable position to assess the 'excellence' of a particular collaboration. Nevertheless, Brussels says it is committed to the principles of peer review by independent experts, and so all leading materials scientists in Europe should be urged to register immediately as potential referees.

If these concerns can be addressed, then despite the seemingly short-term nature of the collaborations, materials scientists should cooperate with these new funding instruments. At first glance, five years may not appear long enough to develop the 'collaborative habit', but Brussels aims to develop lasting integration, which bodes well for future funding of successful FP6 Networks. The likely benefits to European materials research, such as increased opportunity for multidisciplinary collaboration, increased integration between national programmes, and increased pooling of resources to boost Europe's quality of research and competitiveness against Japan and the USA, make it well worth participating. 